\title{
Role of Myo-Inositol by Magnetic Resonance Spectroscopy in Early Diagnosis of Alzheimer's Disease in APP/PS1 Transgenic Mice
}

\author{
Shuang-Qing Chen ${ }^{\mathrm{a}}$ Pei-Jun Wang ${ }^{\mathrm{a}}$ Gao-Jun Ten ${ }^{\mathrm{b}, \mathrm{c}}$ Wei Zhan ${ }^{\mathrm{a}}$ Ming-Hua Li ${ }^{\mathrm{a}}$ \\ Feng-Chao Zang ${ }^{c}$ \\ a Department of Radiology, Tongji Hospital, Tongji University, Shanghai, and ${ }^{\mathrm{b}}$ Department of Radiology, and \\ cMolecular Imaging Laboratory, Zhongda Hospital, Southeast University, Nanjing, China
}

\section{Key Words}

Alzheimer's disease $\cdot$ Magnetic resonance spectroscopy •

Astrocyte $\cdot$ Myo-inositol

\begin{abstract}
Background/Aims: To explore the potential value of myoinositol (mIns), which is regarded as a biomarker for early diagnosis of Alzheimer's disease, in APP/PS1 transgenic (tg) mice detected by ${ }^{1} \mathrm{H}-\mathrm{MRS}$. Methods: ${ }^{1} \mathrm{H}$-MRS was performed in $30 \mathrm{APP} / \mathrm{PS} 1 \mathrm{tg}$ mice and 20 wild-type (wt) littermates at 3, 5 and 8 months of age. Areas under the peak of $\mathrm{N}$-acetylaspartate (NAA), $\mathrm{mlns}$ and creatine $(\mathrm{Cr})$ in the frontal cortex and hippocampus were measured, and the NAA/Cr and $\mathrm{mlns} / \mathrm{Cr}$ ratios were analyzed quantitatively. Results: Compared with the wt mice, the $\mathrm{mlns} / \mathrm{Cr}$ ratio of the 3-month-old tg mice was significantly higher $(p<0.05)$, and pathology showed activation and proliferation of astrocytes in the frontal cortex and hippocampus. The concentration of NAA was significantly lower at 8 and 8 months of age $(p<0.05)$. According to the threshold of $\mathrm{mlns} / \mathrm{Cr}$ that was adopted to separate the $\mathrm{tg}$ from the wt mice, the rate of correct predictions was 82,94 and $95 \%$, respectively, for 3, 5 and 8 months. Conclusion: Of the early AD metabolites as detected by ${ }^{1} \mathrm{H}-\mathrm{MRS}$, $\mathrm{mlns}$ is the most valuable marker for assessment of $A D$. Quantitative analysis of mlns may provide important clues for early diagnosis of AD.

Copyright $\odot 2010$ S. Karger AG, Basel
\end{abstract}

\section{Introduction}

Alzheimer's disease (AD) is a neurodegenerative disease in the elderly, the exact etiology of which is not clear. Senile plaques (SP), neuronal loss and neurofibrillary tangles (NFT) are characteristic pathologic changes of $\mathrm{AD}$ [1]. With the progression of aging populations, the incidence of $\mathrm{AD}$ is increasing gradually [2]. However, medical treatment is only effective in patients with early $\mathrm{AD}$ or those who have mild cognitive impairment (MCI) without presenting irreversible neuronal change, and only early medical intervention may block or delay the progression of $\mathrm{AD}$ and improve the patient's quality of life. Therefore, early detection and treatment of AD have become the focus of $\mathrm{AD}$ research at present.

In the last decade, neuroimaging has been used to complement clinical assessments in the early detection of AD. However, previous AD image studies [3-5] mainly focused on morphological change (such as measurement of the hippocampal volume), and its sensitivity and specificity were not high enough. Some studies [6-8] have investigated the cerebral tissue that had undergone metabolic and functional changes before occurrence of abnormal structural changes in the brain. In recent years, swift development of neurological imaging technology gives rise to tremendous changes in medical imaging patterns. Imaging diagnosis of $\mathrm{AD}$ has transformed from single

\section{KARGER}

Fax +41613061234

E-Mail karger@karger.ch

www.karger.com
(C) 2010 S. Karger AG, Basel

$1420-8008 / 09 / 0286-0558 \$ 26.00 / 0$

Accessible online at:

www.karger.com/dem
Pei-Jun Wang

Department of Radiology, Tongji Hospital, Tongji University

No. 389, Xincun Road, Putuo District

Shanghai 200065 (China)

Tel. +86 216611 1206, Fax +86 215695 2231, E-Mail tongjipjwang@ sina.com 
morphologic anatomy to a combination of function and metabolism, rendering it possible to set up safe and effective markers for early diagnosis of AD [9-10]. Magnetic resonance spectroscopy (MRS) is a noninvasive spectroscopy technique for the study of metabolic and biochemical changes of tissues in vivo as well as quantitative analyses of compounds, thus bringing hope for early diagnosis of AD.

It is generally accepted that a decrease in $\mathrm{N}$-acetylaspartate (NAA) is of great value in an early AD study, but there are controversies over the role of myo-inositol (mIns) in the development of AD [11-14]. In the present study, ${ }^{1} \mathrm{H}-\mathrm{MRS}$ of the frontal cortex and hippocampus of APP/ PS1 double transgenic $(\mathrm{tg})$ mice was performed at 3, 5 and 8 months of age. Our aim was to identify the potential value of mIns, which is regarded as a biomarker of early $\mathrm{AD}$, by comparing it with histopathologic changes.

There have been various $\mathrm{AD}$ animal models, but they cannot reflect $\mathrm{AD}$ in a comprehensive and accurate way. Comparatively, cerebral pathologic changes of tg mice are similar to those of humans, and they can be used to simulate part of the neuropathologic changes such as SP formation, proliferation of neuroglial cells and decrease of synapses. In addition, these mice may display behavioral disorders similar to clinical presentations of $\mathrm{AD}$ [15]. As the AD model of APP/PS1 tg mice used in the present study was characterized by the early appearance of $\beta$-amyloid $(A \beta)$ plaques, neuronal degeneration and synaptic loss in the brain, it is a relatively good model for imaging, behavioral and pathologic studies of $\mathrm{AD}$ and will hopefully provide useful experimental clues for the clinical study of AD.

\section{Materials and Methods}

\section{Animals}

APP/PS1 tg mice were purchased from the animal model center of Nanjing University (Nanjing, China); the species was from B6C3-Tg (APPswe, PSEN1dE9) 85Dbo/J line double transgenic mice (original species No. 004462) provided by the National Jackson Animal Center, USA. The animals were raised in an environment, with free access to food and water. The study group included 30 tg mice (19 male and 11 female), and the control group used 20 wild-type (wt, 9 male and 11 female) mice born in the same nest. According to the report [16], the first plaques in the cortex and hippocampus of APP/PS1 tg mice could be detected at 4-6 months, and Bell and Claudio Cuello [17] thought that 8-monthold APP/PS mice represented an early stage of amyloid pathology. Therefore, mice of 3, 5, and 8 months of age were used for the experiment. The studies were approved by the Shanghai Ethics Committee and all experiments were performed in accordance with guidelines from the Chinese Animal Welfare Agency.

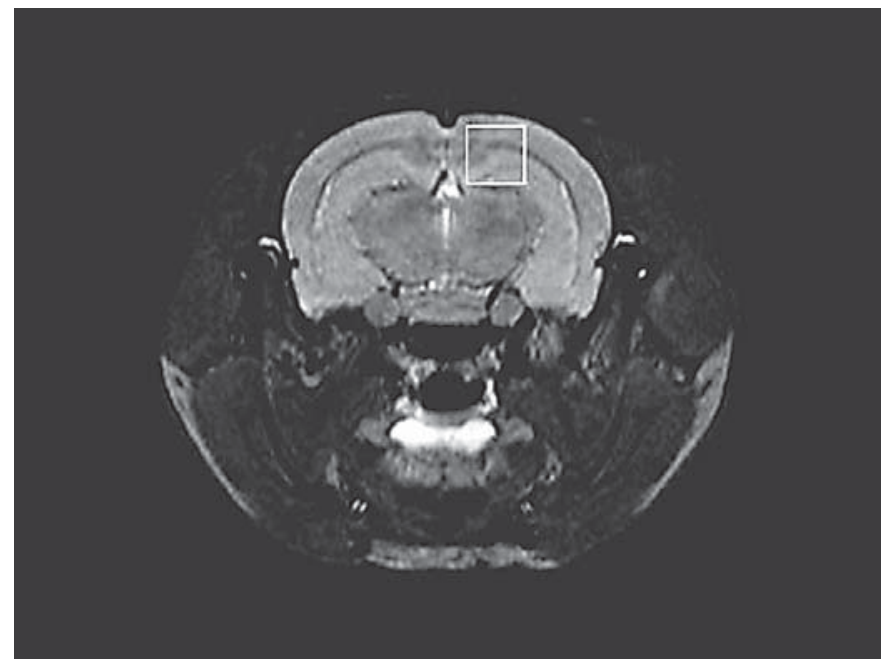

Fig. 1. Localized proton MRS of mice brains in vivo. The region of interest (ROI) was selected in the left side of the mouse brain, including the hippocampus and part of the frontal cortex. ROI sizes were approximately $2.0 \times 2.0 \times 2.0 \mathrm{~mm}$.

\section{MRS Examination}

Mice were anesthetized with $2.0 \%$ isoflurane in an $\mathrm{NO}_{2} / \mathrm{O}_{2}$ mixture. With the teeth hooked by tooth bars, the mice were fixed in a prone position. The body temperature was maintained at $36-$ $37^{\circ} \mathrm{C}$ using a water-heated animal bed, and respiration was monitored. MRI was performed using a 7.0-T magnet with a horizontal bore (Bruker PharmaScan 70/30, Bruker, Germany) equipped with a $12-\mathrm{cm}$ inner diameter self-shielded gradient system (max. gradient strength $300 \mathrm{mTm}^{-1}$ ). The body coil and surface coil were used as the exciting coil and receiving coil, respectively. Using the RARE sequence, axial $\mathrm{T}_{1} \mathrm{WI}$ (TR $500 \mathrm{~ms}$, TE $7.5 \mathrm{~ms}$ ) and $\mathrm{T}_{2} \mathrm{WI}$ (TR 3,000 ms, TE $36 \mathrm{~ms}$ ) and coronal and sagittal $\mathrm{T}_{2} \mathrm{WI}$ were performed with 0.8 - $\mathrm{mm}$ thickness, $1.0-\mathrm{mm}$ interval, $3.0 \times 3.0-\mathrm{mm}$ field of view, and $256 \times 256$ matrix

As amyloid plaques first appeared in the frontal cortex (including the cingulate cortex and sensorimotor cortex) in tg mice $[11,14]$, the region of interest (ROI) was positioned in the hippocampus and part of the frontal cortex in the brain (fig. 1). The voxel size was $2.0 \times 2.0 \times 2.0 \mathrm{~mm}\left(8 \mathrm{~mm}^{3}\right)$. The location was made from the transverse, coronal and sagittal directions, avoiding the surrounding major vessels and lateral ventricular structures. For each animal, great care was taken to reposition the voxel always at the same location. The selected ROI was shimmed and the frequency of water peaks was calculated. The water suppression pulse was adjusted for chemical-shift-water suppression (CHESS) prior to PRESS acquisition. MR spectroscopic data were collected by PRESS at TR 2,500 ms, TE $20 \mathrm{~ms}$ and exciting frequency 500 for $24 \mathrm{~min}$. The original data were treated by the workstation and processed using the Bruker processing software 2D WIN-NMR (Bruker-Franzen Analytik, Germany). Spectral phase diagrams (raw spectra) were Fourier-transformed, baseline-corrected, and zero-filled. The areas under the peak for various metabolites, including mIns, NAA, and $\mathrm{Cr}$, were calculated automatically by the NUTS-NMR Utility Transform Software 
(AcornNMR, Livermore, Calif., USA) [18]. Using $\mathrm{Cr}$ as the criterion, the $\mathrm{mIns} / \mathrm{Cr}$ and $\mathrm{NAA} / \mathrm{Cr}$ ratios were quantified.

\section{Histologic Examination}

After each MR examination, $3 \mathrm{tg}$ mice and $2 \mathrm{wt}$ mice were catheterized by open surgery from the left ventricle to the ascending aorta, through which $100 \mathrm{ml} 4^{\circ} \mathrm{C}$ normal saline was infused quickly, followed by the infusion of $4 \%$ paraformaldehyde solution. The brain was removed, fixed, dehydrated, frozen, sliced into $25-\mu \mathrm{m}$ coronal sections, and stained immunohistochemically with $A \beta$, GFAP, and Nissl.

(1) GFAP fluorescent staining: frozen sections were rinsed with $0.01 \mathrm{~mol} / \mathrm{l} \mathrm{PBS}$, incubated with $3 \%$ hydrogen peroxide for 15 min, treated with $0.3 \%$ Triton X-100 for 30 min, sealed with goat serum for $10 \mathrm{~min}$, added with goat anti mouse GFAP polyclonal antibody (1/400, Sigma, USA), and incubated at $37^{\circ} \mathrm{C}$ for $2 \mathrm{~h}$ and overnight at $4^{\circ} \mathrm{C}$. The secondary antibody was FITC-labeled goat anti-rabbit IgG (1/100, Sigma, USA). To analyze the levels of astrocytes, quantification was performed using a $400 \times$ objective and a $1 \times 1$-mm grid on 15 fields from appropriate consecutive sections of the frontal cortex and hippocampus. Photographs were taken using a fluorescence microscope (Olympus, Japan).

(2) A $\beta$ staining: the first antibody was mouse anti-human $A \beta$ antibody (1/1,000, Sigma, USA), and the secondary antibody was HRP labeled goat anti-mouse IgG (Sigma, USA), incubated at $37^{\circ} \mathrm{C}$ for $2 \mathrm{~h}$, DAB color developed, patched routinely, dehydrated, hyalinized and mounted.

(3) Nissl's staining: frozen sections were stained with $1 \%$ toluidine blue at $56^{\circ} \mathrm{C}$ for $30 \mathrm{~min}$, washed with water, color separated with $95 \%$ ethanol, dehydrated, hyalinized and mounted for microscopic examination.

\section{Statistical Analysis}

Statistical results are expressed as mean \pm SD. All data were statistically analyzed using SPSS 13.0 statistical software. Comparisons of the ${ }^{1} \mathrm{H}$-MRS and histology indexes between tg mice and wt mice at each time point were conducted by a two-sample $t$ test and changes among wt mice of 3,5 and 8 months of age were assessed by means of a one-way ANOVA. $p<0.05$ was considered statistically significant.

To determine whether mIns had any significance in the early diagnosis of $\mathrm{AD}$, the upper limit of the $95 \% \mathrm{CI}$ of the mean mIns/ Cr ratio of the wt mice of 3, 5 and 8 months of age was used as the threshold, and the sensitivity, specificity and correct prediction of the AD mice were compared.

\section{Results}

\section{MRS Examination}

${ }^{1} \mathrm{H}-\mathrm{MRS}$ results of both tg mice and wt mice are shown in table 1. The NAA peak was at $2.0 \mathrm{ppm}$, the mIns peak was at $3.56 \mathrm{ppm}$, and the $\mathrm{Cr}$ peak was at $3.0 \mathrm{ppm}$. Although studies have shown that gender plays an important role in the pathogenesis of AD [19], we do not find significant differences in ${ }^{1} \mathrm{H}$-MRS between male and female mice in any groups in the present study. Compared with the wt mice,
Table 1. Ratio of mIns/Cr and NAA/Cr of tg mice and wt mice at the ages of 3,5 and 8 months

\begin{tabular}{|c|c|c|c|c|}
\hline & \multicolumn{2}{|l|}{$\mathrm{mIns} / \mathrm{Cr}$} & \multicolumn{2}{|l|}{ NAA/Cr } \\
\hline & $\operatorname{tg}$ & wt & $\operatorname{tg}$ & wt \\
\hline 3 months & $0.69 \pm 0.03$ & $0.63 \pm 0.04$ & $1.17 \pm 0.08$ & $1.18 \pm 0.07$ \\
\hline 5 months & $0.71 \pm 0.04$ & $0.64 \pm 0.03$ & $1.04 \pm 0.05$ & $1.16 \pm 0.07$ \\
\hline 8 months & $0.77 \pm 0.04$ & $0.64 \pm 0.04$ & $0.91 \pm 0.05$ & $1.18 \pm 0.08$ \\
\hline
\end{tabular}

Values are expressed as mean $\pm \mathrm{SD}$. The $t$ values of the mIns/ $\mathrm{Cr}$ between tg and wt animals at the ages of 3, 5 and 8 months were $2.803,5.196$ and 15.548 , respectively, and the p values were 0.007 , 0.000 and 0.000 , respectively. The $t$ values of NAA/Cr between $\mathrm{tg}$ and wt animals at the ages of 3,5 and 8 months were $0.758,-8.520$ and -5.645 , respectively, and the $p$ values were $0.452,0.000$ and 0.000 , respectively.

Table 2. Percent sensitivity and specificity

\begin{tabular}{llrll}
\hline Age & $\begin{array}{l}\text { Threshold } \\
\text { value }\end{array}$ & Sensitivity & Specificity & $\begin{array}{l}\text { Total correct } \\
\text { predictions }\end{array}$ \\
\hline 3 months & 0.68 & $80(24 / 30)$ & $85(17 / 20)$ & $82(41 / 50)$ \\
5 months & 0.67 & $96(27 / 28)$ & $89(17 / 19)$ & $94(44 / 47)$ \\
8 months & 0.67 & $100(26 / 26)$ & $89(16 / 18)$ & $95(42 / 44)$ \\
\hline
\end{tabular}

The upper limit of the $95 \%$ CI of the mean mIns/Cr ratio of wt mice was used as the threshold, and the number of correct predictions increased from 82 to $95 \%$ between 3 and 8 months of age.

Table 3. Numbers of GFAP-positive astrocytes in tg and wt mice at different time points $\left(\mathrm{n} / \mathrm{mm}^{2}\right)$

\begin{tabular}{lllrl}
\hline & tg & wt & \multicolumn{1}{l}{$\mathrm{t}$} & \multicolumn{1}{c}{$\mathrm{p}$} \\
\hline 3 months & $15.32 \pm 2.25$ & $10.60 \pm 1.90$ & 7.133 & $<0.001$ \\
5 months & $19.75 \pm 2.24$ & $10.85 \pm 1.95$ & 13.375 & $<0.001$ \\
8 months & $21.15 \pm 2.68$ & $11.15 \pm 2.03$ & 13.291 & $<0.001$ \\
\hline
\end{tabular}

Values are expressed as mean \pm SD.

significant mIns elevation was detected in 3-month-old tg mice, and there was a significant difference in the $\mathrm{mIns} / \mathrm{Cr}$ ratio between the tg and wt mice $(\mathrm{p}<0.05)$. In addition, mIns increased gradually with mouse age. There was no significant change in NAA in 3-month-old tg mice ( $p>$ $0.05)$, a significant decrease in 5 -month-old tg mice ( $\mathrm{p}<$ 0.05 ), and an even greater decrease in 8 -month-old tg mice (fig. 2-4). There was no significant change in NAA and 


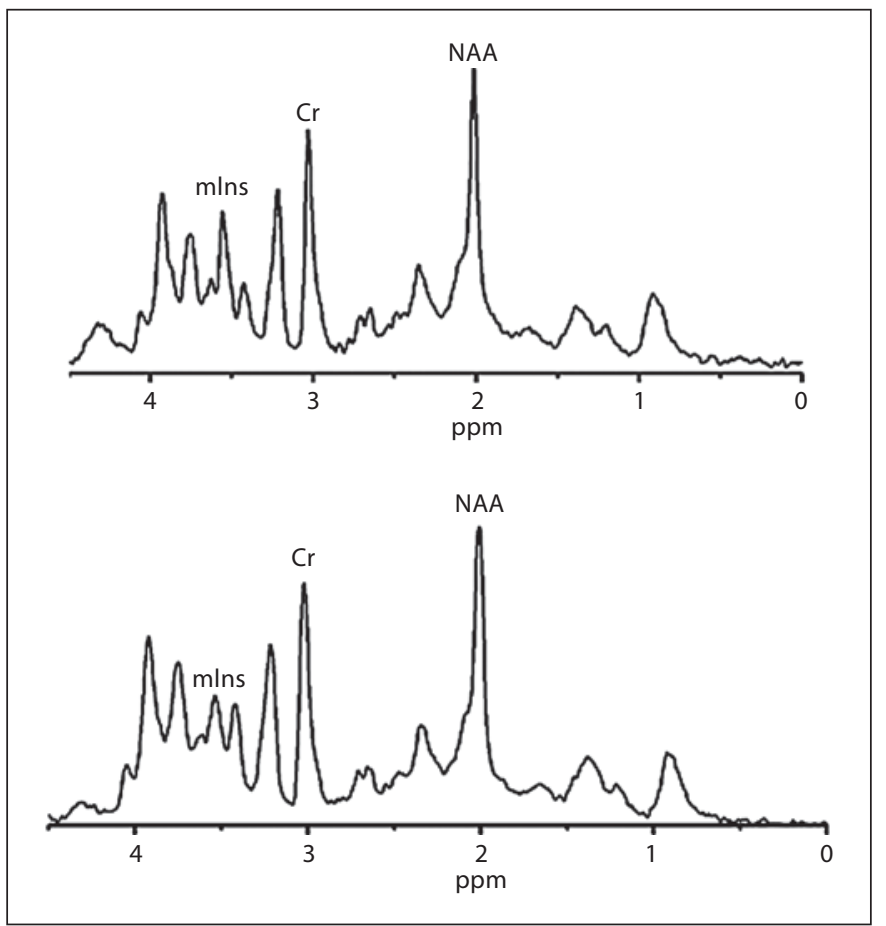

Fig. 2. Spectra from the hippocampus and frontal cortex in tg (top) and in wt mice (bottom) at the age of 3 months. mIns was significantly increasing in the $\operatorname{tg}$ mice, and there was no significant change in NAA.

$\mathrm{mIns}$ in the wt mice at all designated time points ( $\mathrm{F}$ value was 0.37 and 0.53 , respectively, $\mathrm{p}>0.05$ ).

Using the upper limit of $95 \% \mathrm{CI}$ of the mean mIns/Cr ratio of the wt mice of 3,5 , and 8 months of age as the threshold, the sensitivity, specificity and correct prediction of the $\mathrm{AD}$ mice are shown in table 2 . The correct predictions increased from $82 \%$ at 3 months of age to $95 \%$ at 8 months of age.

\section{Histologic Examination}

\section{GFAP Staining}

Table 3 shows the numbers of GFAP-positive cells in tg and wt mice at different time points. Compared with the wt mice, the overall intensity of GFAP immunoreactivity of the tg mice increased considerably at 3,5 , and 8 months of age $(\mathrm{p}<0.001)$. As shown in figure $5 \mathrm{a}-\mathrm{c}$ for the hippocampi of 3-month-old tg mice, the astrocyte somata had a larger appearance in the field and GFAP staining was more intense than in wt mice. From 5 to 8 months of age, the astrocyte proliferation of tg mice was apparent in a much larger area. GFAP-positive cells were seen interlocking into masses in 8-month-old $\mathrm{AD}$ mice.

Study of Magnetic Resonance

Spectroscopy in AD

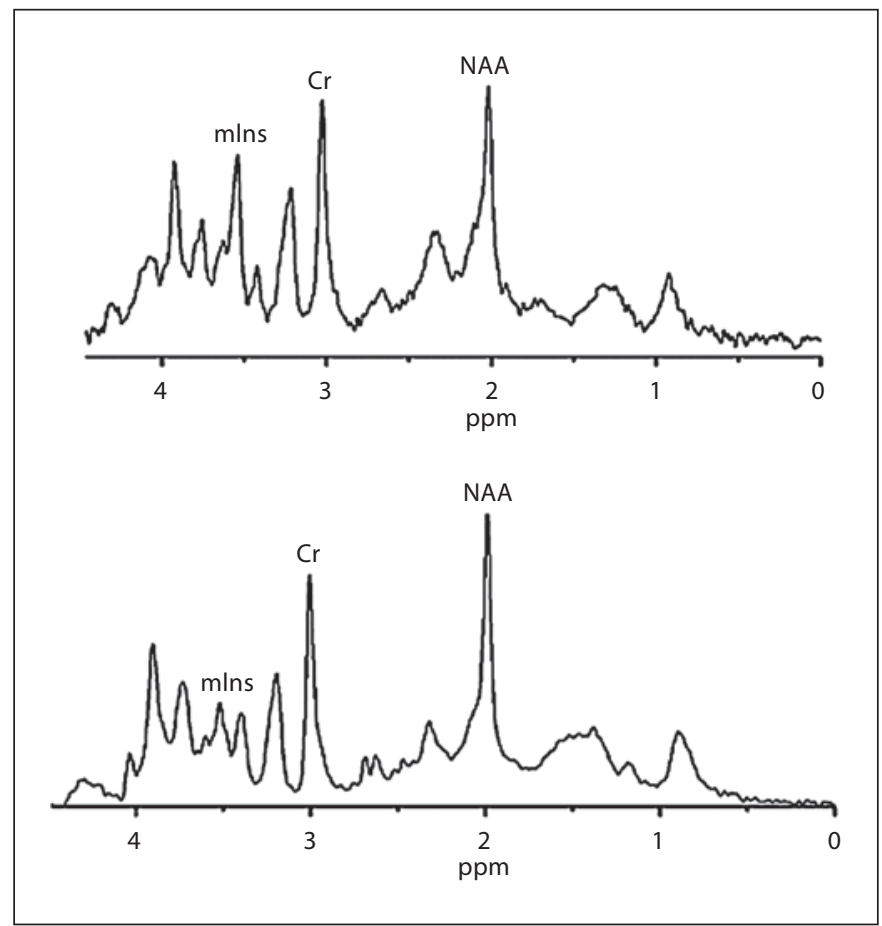

Fig. 3. Spectra from the hippocampus and frontal cortex in tg (top) and in wt mice (bottom) at the age of 5 months. The NAA/Cr ratios of the tg mice decreased significantly.

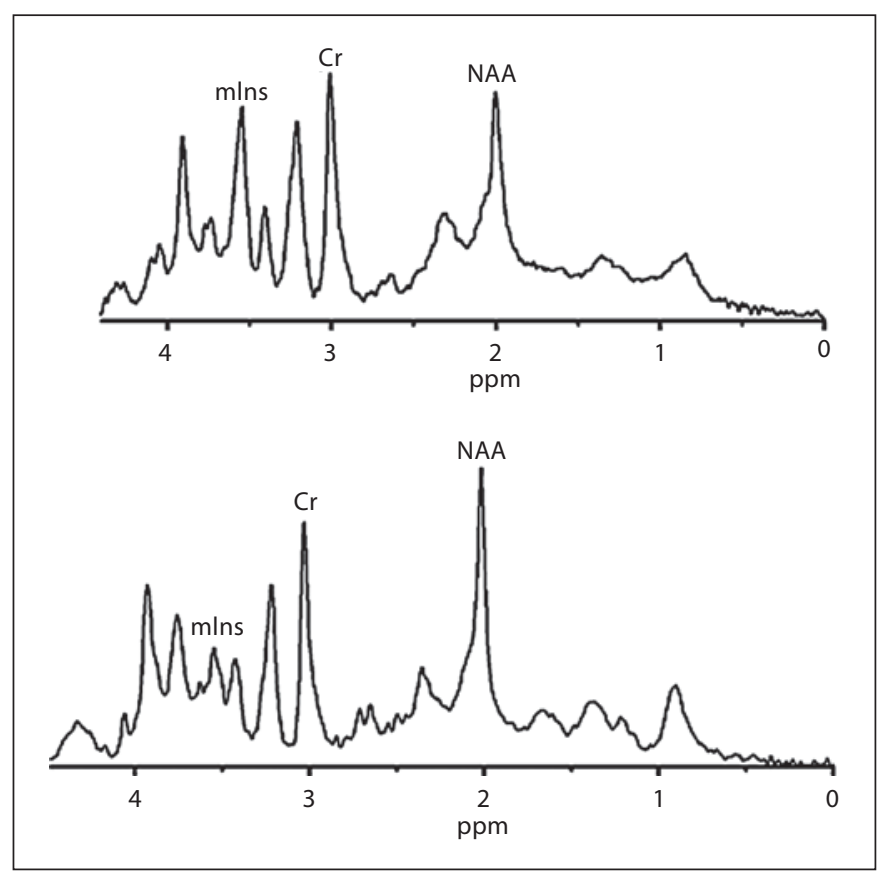

Fig. 4. Spectra from the hippocampus and frontal cortex in tg (top) and in wt mice (bottom) at the age of 8 months. There were more remarkable changes for mIns and NAA in the tg mice.

Dement Geriatr Cogn Disord 2009;28:558-566 

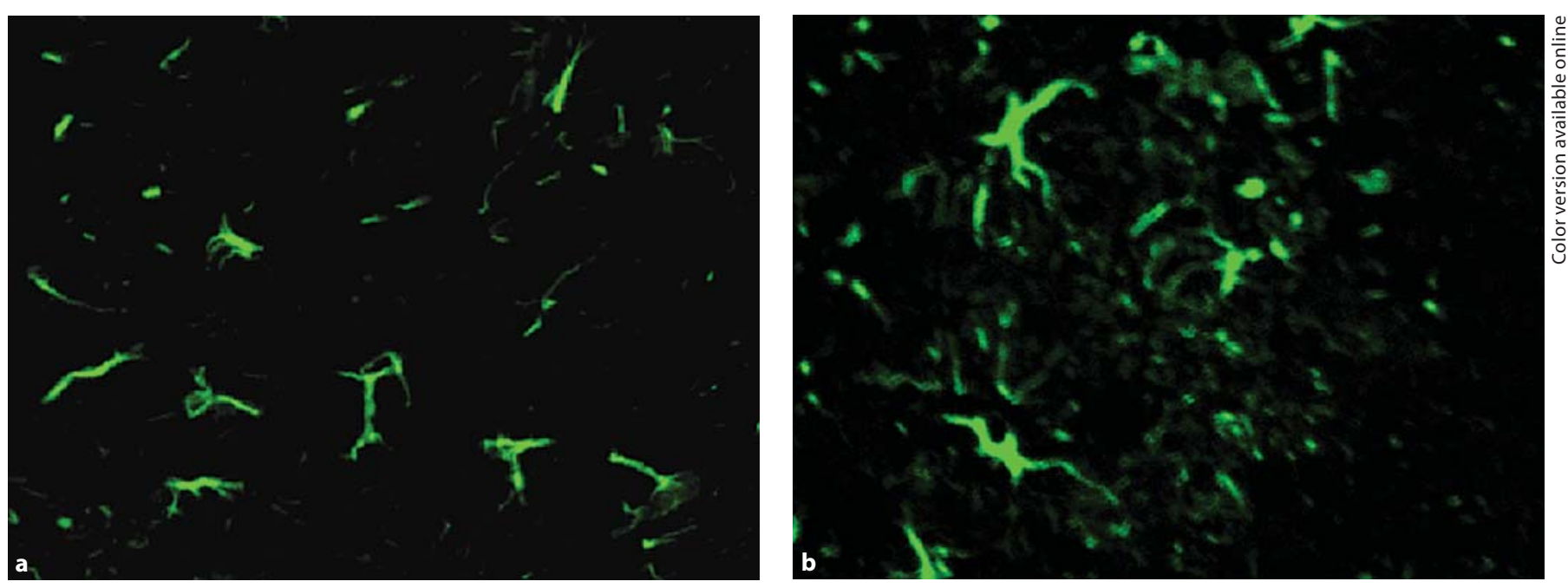

Fig. 5. GFAP fluorescent staining. a Expression of GFAP in the hippocampus of 3-month-old wt mice. Immunofluorescence FITC staining. $\times 200$. $\mathbf{b}$ In the hippocampus of 3 -month-old tg mice, reactive astrocytes had a larger appearance than in wt mice. The activated astrocytes displayed an altered size and morphology. Immunofluorescence FITC staining. $\times 200$. c GFAP-positive cells were seen interlocking into masses in 8-month-old tg mice. Immunofluorescence FITC staining. $\times 400$.

\section{A $\beta$ Staining}

A histologic examination revealed that no $A \beta$ plaques were seen in the observation areas of 3-month-old tg mice (fig. 6a), although astrocyte reactivity was detected. A small number of diffuse $A \beta$ deposits were seen in the frontal cortex and hippocampus in 5-month-old tg mice (fig. 6b). In 8-month-old tg mice, many brown extracellular deposits were detected compared with mice 5 months of age, and compact plaques were seen in the hippocampus (fig. $6 \mathrm{c}$ ). In addition, no $\mathrm{A} \beta$ plaques were found in wt animals at any time points.

\section{Nissl's Staining}

Neurons were seen in good and dense arrangement, and the Nissl bodies were rich in cytoplasm in the hippocampus of 3-month-old tg mice (fig. 7a). In 5-month-

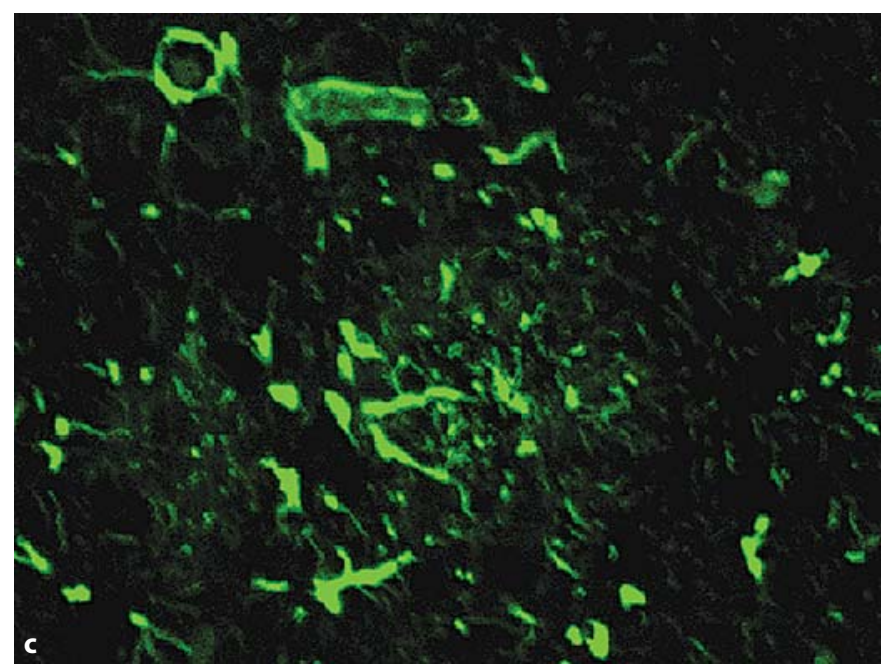

old tg mice, the number of neurons gradually decreased, the arrangement became sparse, the intercellular space widened (fig. $7 b$ ). With the increase of $A \beta$ plaques in the hippocampus, Nissl bodies in the cytoplasm decreased or disappeared, and large patches of cells were lost in 8month-old tg mice (fig. 7c).

\section{Discussion}

Magnetic resonance spectroscopy is a spectral technique for the assessment of several biochemical compounds in vivo and in vitro. ${ }^{1} \mathrm{H}-\mathrm{MRS}$ is the most commonly used technique that permits the quantification of metabolic biomarkers of the brain, and has been used to characterize Alzheimer's disease. In the present experi- 

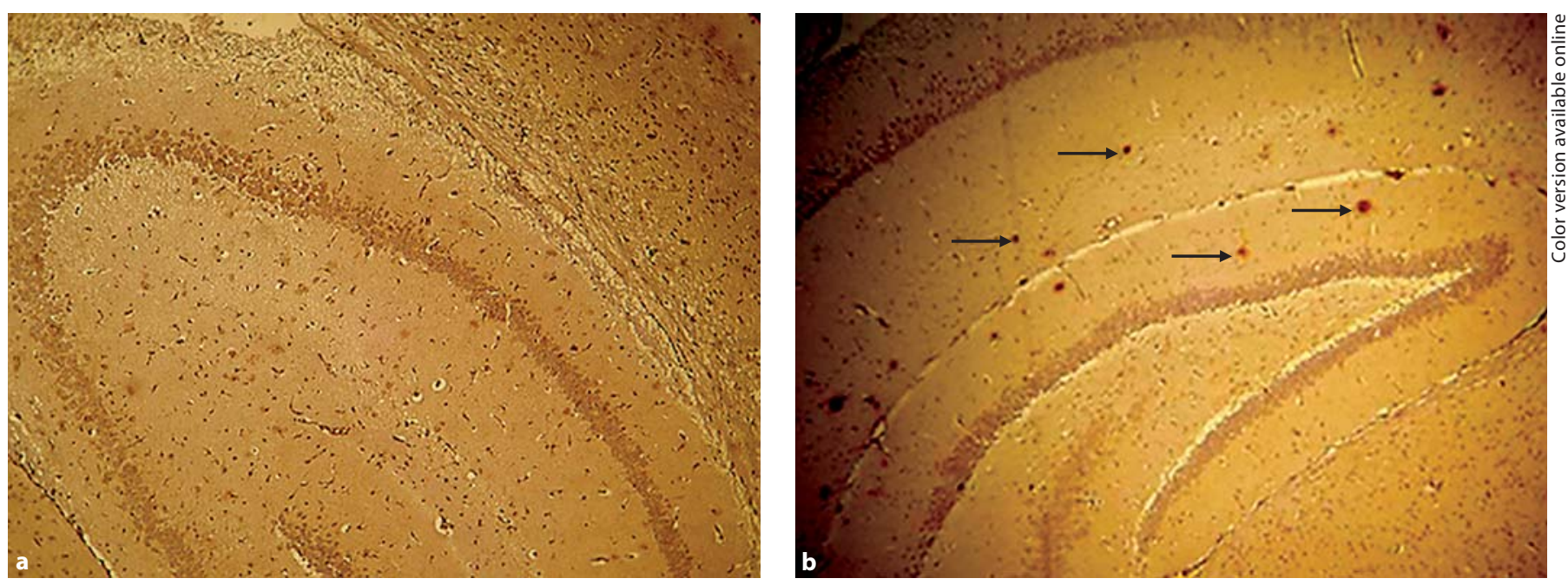

Fig. 6. $A \beta$ staining. a No $A \beta$ plaques were seen in the observation areas of 3-month-old tg mice. Immunohistochemical staining. $\times 200$. b In 5 -month-old tg mice, there were small, scattered brown (arrows) deposits in the hippocampus. Immunohistochemical staining. $\times 200$. c In higher magnitude, a neuritic plaque was seen in the observation areas of 8 -month-old tg mice. Immunohistochemical staining. $\times 400$.

ment, we used a single voxel PRESS sequence on a 7.0-T high-field MR to conduct stable quantitative measurement of mIns, NAA and Cr in the brain of APP/PS1 double transgenic $\mathrm{AD}$ mice.

Numerous studies [20-23] have demonstrated that NAA, a marker of neurons, can be used to differentiate normal aging and pathologic dementia effectively. The results of our study also showed that NAA was reduced significantly in the frontal cortex and hippocampus of 5 month-old APP/PS1 tg mice, when pathology showed the formation of sparse $A \beta$ plaques in these areas, and the number of neurons decreased. As the age of the mice increased, the number of $A \beta$ plaques gradually increased, and the number and density of Nissl-positive cells also gradually decreased. NAA decreased continuously on ${ }^{1} \mathrm{H}$-MRS. These findings fully reflect the pathologic pro-

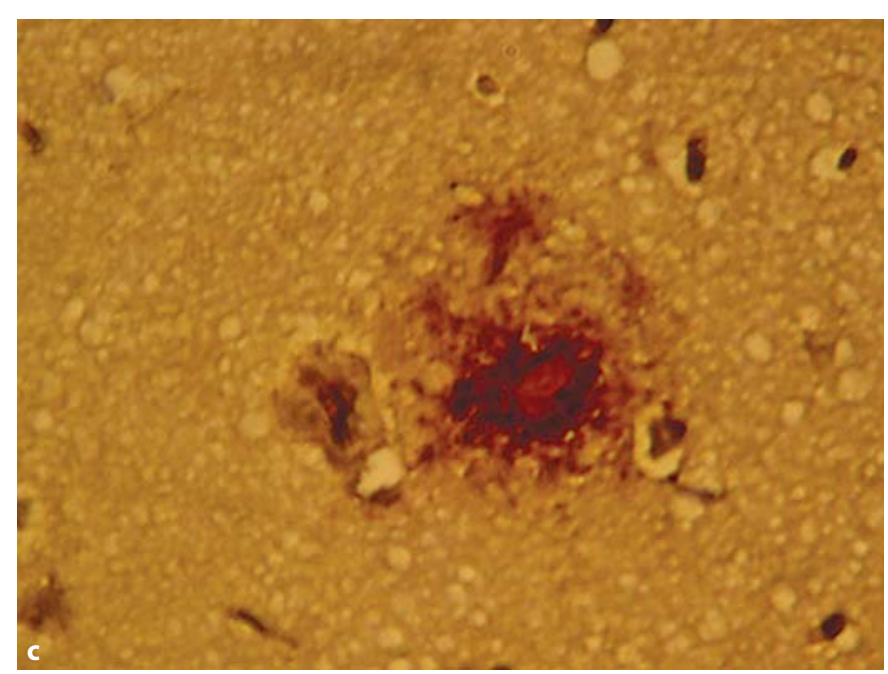

cess of the degeneration of neurons induced by the toxicity of $A \beta$ protein deposition.

mIns is a marker of neuroglial cells and exists in the astrocytes of brain tissue. It is an organic substance regulating the osmotic pressure of neuroglial cells and maintaining the stability of the volume of neuroglial cells. In the present study, mIns increased significantly in 3month-old tg mice. No significant change in NAA was observed, nor were there pathologic $A \beta$ plaques in the brain of tg mice, or significant neuronal changes in the hippocampal areas. The result indicated that the change in mIns was significant in differentiating APP/PS1 tg mice from wt mice. Marjanska et al. [12] also found in their observation of $27 \mathrm{APP} / \mathrm{PS} 1$ double transgenic AD mice that mIns increased gradually with age, but that the phenomenon was not observed in the APP model mice. 


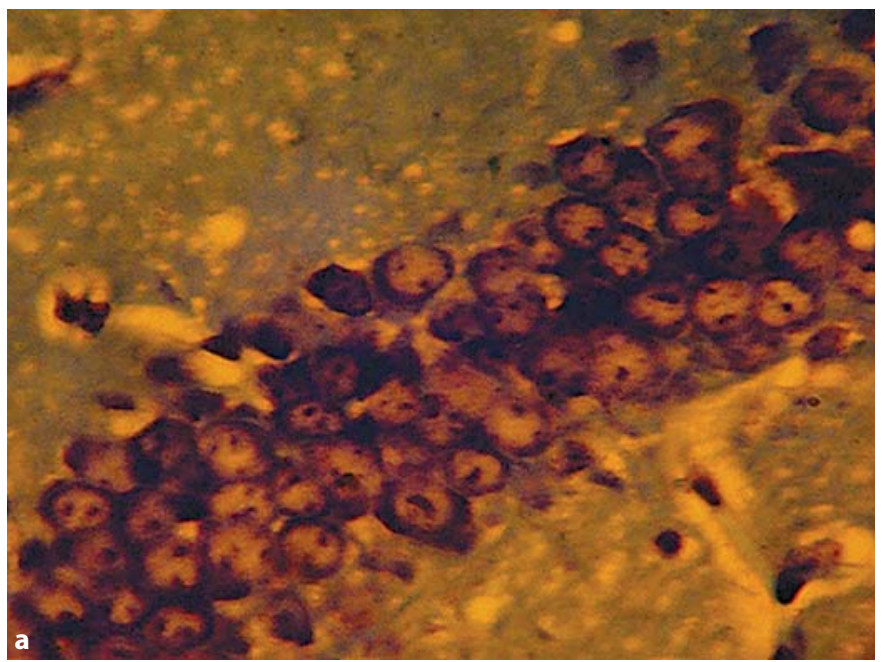

Fig. 7. Nissl's staining (immunohistochemical staining, $\times 400$ ). a Neurons were seen in dense arrangement, and the Nissl bodies were rich in cytoplasm in the hippocampus of 3-month-old tg mice. $\mathbf{b}$ Arrangement of neurons is sparse, and there was slight neuronal shrinkage in the hippocampus of 5-month-old tg mice. c Nissl bodies in the cytoplasm decreased or disappeared in the hippocampus of 8-month-old tg mice.

We speculated that the inconsistent result might be responsible for the model of AD mice. For example, no increase in mIns was observed in the case of PS2APP mice [11]. Likewise, Dedeoglu et al. [14] found that there was no significant change in mIns in 19-month-old APP mice. However, Oberg et al. [13] found in their study of ${ }^{1} \mathrm{H}-\mathrm{MRS}$ of 2.5-, 6.5- and 9-month-old APP/PS1 tg mice that mIns in 2.5-month-old tg mice was even lower than that of their control animals. Further studies need to be performed to determine whether different study methods result in diverse conclusions (selected ROI, parameters used, etc.).

The exact mechanism of mIns abnormality prior to NAA remains unclear, and there are no related reports about this. However, some studies have suggested that elevated mIns levels are characterized by excessive brain
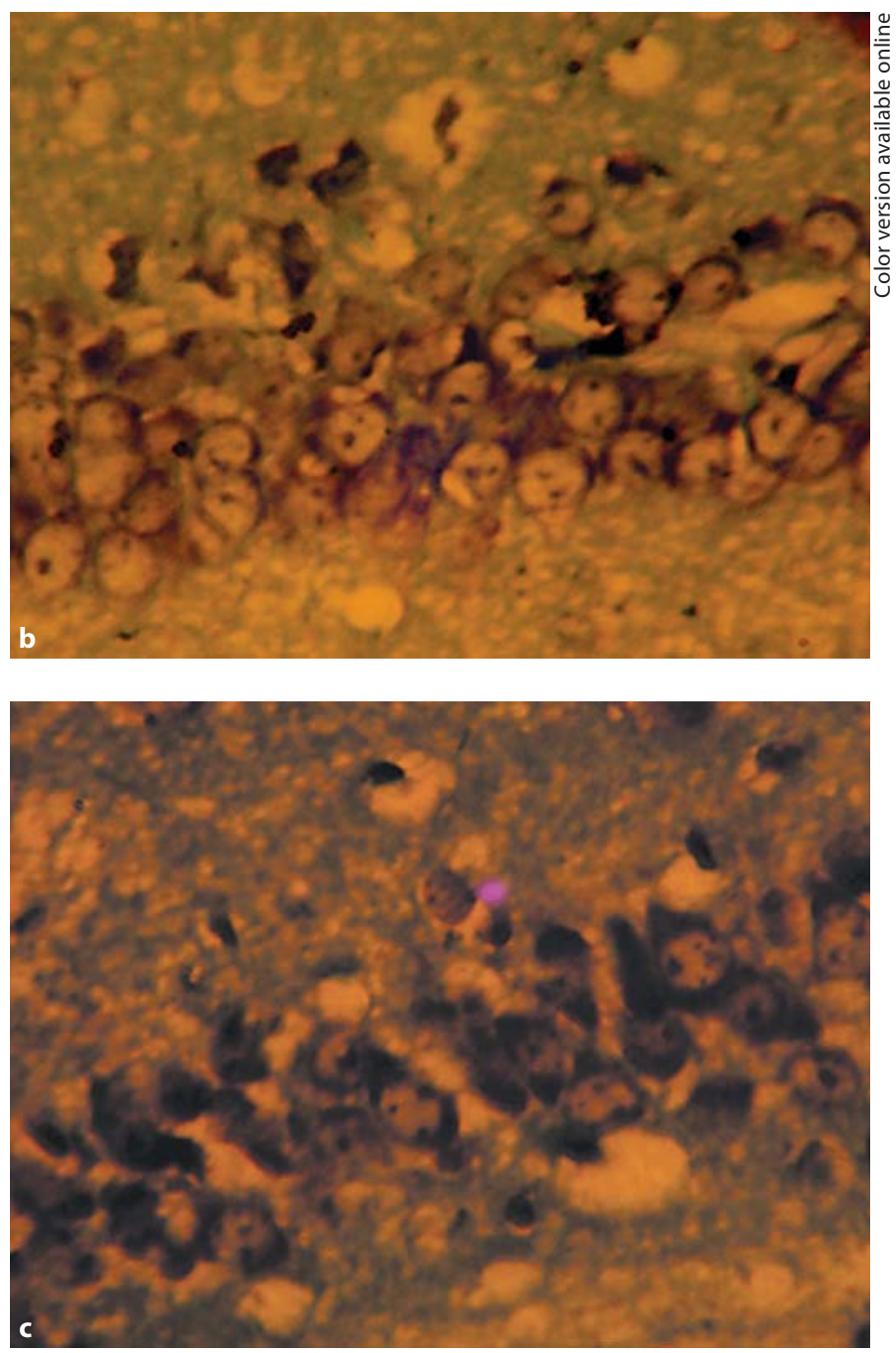

gliosis. For example, Behar et al. [24] believe that the rise in mIns corresponds to the most marked astrocytic reaction and might reflect a specific glial response in hamsters with Creutzfeldt-Jakob disease. Coimbra et al.'s studies have shown a correlation of increased mIns with AD pathology [25]. In the present study, the results of GFAP staining showed that there were activated and hyperplastic astrocytes in the frontal cortex and hippocampus of 3-month-old AD mice, while no $A \beta$ plaques were detected and neurons were also not abnormally damaged. This result indicated that an increase in mIns was related to the activation and reactive hyperplasia of astrocytes. Jacobsen et al. [26] found that there was no significant $A \beta$ increase in the brain of TG transgenic AD mice younger than 18 months, while the GFAP expression increased markedly, with enlarged cell bodies. Kimura et 
al. [27] believed that the response of astrocytes to $A \beta$ may have been enhanced before the typical AD pathologic change appeared. Obviously, under pathologic conditions in which the stable environment of the central nervous system undergoes changes, astrocytes can quickly transform from the resting state to an active state. Studies showed that astrocytes had the action of dispersing, degrading and phagocytosing the $A \beta$ protein, preventing $\mathrm{A} \beta$ from aggregating and depositing, and maintaining the microenvironment of CNS cells in the early phase of AD. For example, Das and Golde [28] found that TGF- $\beta 1$ secreted by astrocytes was able to clear $A \beta$ by activating microglial cells, thus decreasing the formation of senile plaques and protecting nerves. Wyss-Coray et al. [29] also found that astrocytes participated directly in the $A \beta$ degradation process. For this reason, there was only hyperplasia of glial cells without significant damage to neurons in 3-month-old AD mice, when there was only an increase in mIns without a significant change in NAA as detected by ${ }^{1} \mathrm{H}-\mathrm{MRS}$.

The early detection of $\mathrm{AD}$ is of great significance for clinical treatment. There have been many clinical studies using ${ }^{1} \mathrm{H}$-MRS to conduct $\mathrm{AD}$ research in vivo [7, 30-32]. Kantarci et al. [30] pointed out that an mIns/Cr increase could reflect the pathologic condition of $\mathrm{AD}$ earlier than the NAA/Cr reduction. Huang et al. [31] also found that the change in mIns occurred earlier than the NAA change in $\mathrm{AD}$ patients. However, as there is a lack of experimental animal studies and pathologic controls, there is no conclusion about the tendency and critical level of change of these metabolic indexes, and therefore it is impossible to set up a series of AD spectra for the early diagnosis of $\mathrm{AD}$ at present. In the present study, we used the upper limit of $95 \%$ CI of the mIns/Cr ratio of the wt mice as the critical point for $\mathrm{AD}$ judgment, and the results showed that the correct predictions were 82,94 and $95 \%$, respectively, in 3-, 5- and 8-month-old mice. This result indicates that mIns may be used as a sensitive and specific marker of early AD. Our study may hopefully provide useful experimental clues for further study of AD. However, further studies need to be performed since the APP/ PS1 is only an animal model of AD pathology and only reflects one aspect of the disease.

In the present study, we conducted quantitative analyses of mIns in APP/PS1 tg mice by means of ${ }^{1} \mathrm{H}-\mathrm{MRS}$. By comparing the ${ }^{1} \mathrm{H}-\mathrm{MRS}$ results with pathologic findings, we found that mIns levels became elevated before neurons underwent significant change in early $\mathrm{AD}$. We believe that $\mathrm{mIns} / \mathrm{Cr}$ elevation is one of the most direct cues for early diagnosis of $\mathrm{AD}$, and may prove to be a new method of assisting clinical diagnosis of $\mathrm{AD}$ and observing progression of the condition.

\section{Acknowledgments}

This research was supported by grants from Key Project on Basic Research of Shanghai (07jc14054). We also thank Wang Li for her assistance with the immunohistochemical staining with A $\beta$, GFAP, and Nissl.

\section{References}

1 Frey HJ, Mattila KM, Korolainen MA, Pirttilä T: Problems associated with biological markers of Alzheimer's disease. Neurochem Res 2005;30:1501-1510.

-2 Villemagne VL, Rowe CC, Macfarlane S, Novakovic KE, Masters CL: Imaginem oblivionis: the prospects of neuroimaging for early detection of Alzheimer's disease. J Clin Neurosci 2005; 12:221-230.

$\checkmark 3$ Pennanen C, Kivipelto M, Tuomainen S, Hartikainen P, Hänninen T, Laakso MP, Hallikainen M, Vanhanen M, Nissinen A, Helkala EL, Vainio P, Vanninen R, Partanen $\mathrm{K}$, Soininen H: Hippocampus and entorhinal cortex in mild cognitive impairment and early AD. Neurobiol Aging 2004;25:303310.
-4 Basso M, Yang J, Warren L, MacAvoy MG, Varma P, Bronen RA, van Dyck CH: Volumetry of amygdala and hippocampus and memory performance in Alzheimer's disease. Psychiatry Res 2006;146:251-261.

$\checkmark 5$ den Heijer T, Geerlings MI, Hoebeek FE, Hofman A, Koudstaal PJ, Breteler MM: Use of hippocampal and amygdalar volumes on magnetic resonance imaging to predict dementia in cognitively intact elderly people. Arch Gen Psychiatry 2006;63:57-62.

-6 Lehéricy S, Marjanska M, Mesrob L, Sarazin M, Kinkingnehun S: Magnetic resonance imaging of Alzheimer's disease. Eur Radiol 2007; 17:347-362.

7 Metastasio A, Rinaldi P, Tarducci R, Mariani E, Feliziani FT, Cherubini A, Pelliccioli GP, Gobbi G, Senin U, Mecocci P: Conversion of MCI to dementia: role of proton magnetic resonance spectroscopy. Neurobiology of Aging 2006;27:926-932.
$>8$ Huang W, Alexander GE, Daly EM, Shetty HU, Krasuski JS, Rapoport SI, Schapiro MB: High brain myo-inositol levels in the predementia phase of Alzheimer's disease in adults with Down's syndrome: a ${ }^{1} \mathrm{H}$ MRS study. Am J Psychiatry 1999;156:1879-1886.

$\checkmark 9$ Michaelis T, Boretius S, Frahm J: Localized proton MRS of animal brain in vivo: Models of human disorders. Prog Nucl Magn Reson Spectrosc 2009;55:1-34.

10 Falini A, Bozzali M, Magnani G, Pero G, Gambini A, Benedetti B, Mossini R, Franceschi M, Comi G, Scotti G, Filippi M: A whole brain MR spectroscopy study from patients with Alzheimer's disease and mild cognitive impairment. Neuroimage 2005;26: 1159-1163. 
-11 von Kienlin M, Künnecke B, Metzger F, Steiner G, Richards JG, Ozmen L, Jacobsen $\mathrm{H}$, Loetscher H: Altered metabolic profilein the frontal cortex of PS2APP transgenic mice, monitored throughout their life span. Neurobiol Dis 2005;18:32-39.

-12 Marjanska M, Curran GL, Wengenack TM, Henry PG, Bliss RL, Poduslo JF, Jack CR Jr, Uqurbil K, Garwood M: Monitoring disease progression in transgenic mouse models of Alzheimer's disease with proton magnetic resonance spectroscopy. Proc Natl Acad Sci USA 2005; 102:11906-11910.

-13 Oberg J, Spenger C, Wang FH, Andersson A, Westman E, Skoglund P, Sunnemark D, Norinder U, Klason T, Wahlund LO, Lindberg M: Age related changes in brain metabolites observed by ${ }^{1} \mathrm{H}-\mathrm{MRS}$ in APP/PS1 mice. Neurobiol Aging 2008;29:1423-1433.

- 14 Dedeoglu A, Choi JK, Cormier K, Kowall NW, Jenkins BG: Magnetic resonance spectroscopic analysis of Alzheimer's disease mouse brain that express mutant human APP shows altered neurochemical profile. Brain Res 2004;1012:60-65.

$\checkmark 15$ Oddo S, Caccamo A, Shepherd JD, Murphy MP, Golde TE, Kayed R, Metherate R, Mattson MP, Akbari Y, LaFerla FM: Triple-transgenic model of Alzheimer's disease with plaques and tangles: intracellular Abeta and synaptic dysfunction. Neuron 2003;39:409421.

16 Bloom FE, Reilly JF, Redwine JM, Wu CC, Young WG, Morrison JH: Mouse models of human neurodegenerative disorders: requirements for medication development. Arch Neurol 2005;62:185-187.

$\checkmark 17$ Bell KF, Claudio Cuello A: Altered synaptic function in Alzheimer's disease. Eur J Pharmacol 2006;545:11-21.
18 Hoyer K, Krenz M, Robbins J, Ingwall JS: Shifts in the myosin heavy chain isozymes in the mouse heart result in increased energy efficiency. J Mol Cell Cardiol 2007;42:214221.

19 Wang J, Tanila H, Puoliväli J, Kadish I, van Groen T: Gender differences in the amount and deposition of amyloid in $\beta$ APPswe and PS1 double transgenic mice. Neurobiol Dis 2003;14:318-327.

20 Jones RS, Waldman AD: ${ }^{1} \mathrm{H}-\mathrm{MRS}$ evaluation of metabolism in Alzheimer's disease and vascular dementia. Neurol Res 2004;26:488495.

21 Jessen F, Traeber F, Freymann N, Maier W, Schild HH, Heun R, Block W: A comparative study of the different $\mathrm{N}$-acetylaspartate measures of the medial temporal lobe in $\mathrm{Alz}$ heimer's disease. Dement Geriatr Cogn Disord 2005;20:178-183.

22 den Heijer T, Sijens PE, Prins ND, Hofman A, Koudstaal PJ, Oudkerk M, Breteler MM: MR spectroscopy of brain white matter in the prediction of dementia. Neurology 2006; 66:540-544.

23 Ackl N, Ising M, Schreiber YA, Atiya M, Sonntag A, Auer DP: Hippocampal metabolic abnormalities in mild cognitive impairment and Alzheimer's disease. Neurosci Lett 2005;384:23-28.

24 Behar KL, Boucher R, Fritch W, Manuelidis $\mathrm{L}$ : Changes in $\mathrm{N}$-acetylaspartate and myoinositol detected in the cerebral cortex of hamsters with Creutzfeldt-Jakob disease. Magn Reson Imaging 1998;16:963-968.

25 Coimbra A, Williams DS, Hostetler ED: The role of MRI and PET/SPECT in Alzheimer's disease. Curr Top Med Chem 2006;6:629647.
26 Jacobsen JS, Wu CC, Redwine JM, Comery TA, Arias R, Bowlby M, Martone R, Morrison JH, Pangalos MN, Reinhart PH, Bloom FE: Early-onset behavioral and synaptic deficits in a mouse model of Alzheimer's disease. Proc Natl Acad Sci USA 2006;103:51615166.

-27 Kimura N, Takahashi M, Tashiro T, Terao K: Amyloid beta up-regulates brain-derived neurotrophic factor production from astrocytes: rescue from amyloid beta-related neuritic degeneration. J Neurosci Res 2006;84: 782- 789 .

28 Das P, Golde T: Dysfunction of TGF- $\beta$ signaling in Alzheimer's disease. J Clin Invest 2006; 116:2855-2857.

-29 Wyss-Coray T, Lin C, Yan F, Yu GQ, Rohde M, McConlogue L, Masliah E, Mucke L: TGF-betal promotes microglial amyloidbeta clearance and reduces plaque burden in transgenic mice. Nat Med 2001;7:612-618.

-30 Kantarci K, Petersen RC, Boeve BF, Knopman DS, Tang-Wai DF, O’Brien PC, Weigand SD, Edland SD, Smith GE, Ivnik RJ, Ferman TJ, Tangalos EG, Jack CR Jr: ${ }^{1} \mathrm{H}-\mathrm{MRS}$ spectroscopy in common dementias. Neurology 2004;63:1393-1398.

>31 Huang W, Alexander GE, Chang L, Shetty HU, Krasuski JS, Rapoport SI, Schapior MB: Brain metabolite concentration and dementia severity in Alzheimer's disease: a ${ }^{1} \mathrm{H}-\mathrm{MRS}$ study. Neurology 2001;57:626-632.

32 Godbolt AK, Waldman AD, MacManus DG, Schott JM, Frost C, Cipolotti L, Fox NC, Rossor MN: MRS shows abnormalities before symptoms in familial Alzheimer disease. Neurology 2006;66:718-722. 